BARBARA CZAJA ${ }^{1}$

Muzeum Pałacu Króla Jana III w Wilanowie

ORCID 0000-0001-9556-0489

\title{
OD BLEU-MOURANT DO ZIELENI. XVIII-WIECZNY WELUR WZORZYSTY Z PALACU WILANOWSKIEGO
}

\section{From Bleu-mourant to Green: $18^{\text {th }}$-century Patterned Velvet from the Wilanów Palace Abstract}

A new textile decoration was introduced in the first half of the $18^{\text {th }}$ century in the royal apartments of the Wilanów Palace. The walls of the King's Bedroom were decorated with costly ornamental velvet, most likely brought from Italy. Following research and a series of analyses of the state of preservation of textiles in the King's Bedroom, in 2005 it was decided to take down the original velvet. The most extensive damage was caused by longtime unrestricted exposure to UV and IR irradiation, which resulted in irreversible physico-chemical and optical changes. In the course of three hundred years, the colour of the fabric had undergone the transformation and become greyed yellow-green. The original colour of the velvet can be observed at the seams and under the trimmings of the fabrics.

Keywords: patterned velvet, wall fabrics, King's Bedroom, bleu mourant, abrash

\begin{abstract}
Abstrakt
W pierwszej połowie XVIII wieku w apartamentach królewskich pałacu w Wilanowie pojawił się nowy wystrój tekstylny. Ściany Sypialni Króla zostały udekorowane kosztownym welurem wzorzystym pochodzącym najprawdopodobniej z Włoch. W 2005 roku po badaniach i licznych analizach stanu zachowania tkanin z Sypialni Króla zadecydowano o zdjęciu ze ścian oryginalnego weluru. Największe zniszczenia zostały spowodowane przez długotrwałe, nieograniczone wystawienie tkanin ściennych na działanie promieniowania UV i IR, które przyczyniło się do nieodwracalnych fizyko-chemicznych i optycznych zmian. Na przestrzeni trzystu lat kolor tkanin uległ zmianie i stał się szarożółtozielony. Pierwotny kolor weluru można było dostrzec przy szwach i pod dekorującymi go galonami.
\end{abstract}

Słowa kluczowe: welur wzorzysty, tkaniny ścienne, Sypialnia Króla, bleu mourant, abrasz Barbara Czaja - archeolog, konserwator zabytków w Muzeum Pałacu Króla Jana III w Wilanowie, opiekun
kolekcji tkanin, ubiorów i akcesoriów mody oraz mebli tapicerowanych. Wielokrotnie brała udział w wykopali-
skach w Egipcie (Naqlun, Sheikh Abd el Ghurna, Deir El Baharii, Berenike) i Sudanie (Dongola) jako specjalistka
od tkanin. Autorka publikacji na temat konserwacji tkanin oraz tkanin archeologicznych. E-mail: czajabarbara@
yahoo.com. 
@ypialnię Króla znajdującą się w najstarszej części letniej rezydencji króla Jana SobieSkiego w Wilanowie zdobi jedwabny welur wzorzysty (fr. velours de Gênes), tzw. welur cięty (fr. velours coupé), utkany pomiędzy 1710 i 1720 rokiem być może we Włoszech (il.1). Nowa aranżacja tekstylna tego apartamentu została zainicjowana przez hetmanową wielką koronną Elżbietę Sieniawską, właścicielkę rezydencji, która kupiła pałac w 1720 roku od królewicza Konstantego, syna Jana III. Zamierzeniem Sieniawskiej było wykorzystanie niezwykle dekoracyjnego i cennego wzorzystego weluru jako ram dla gładkich płaszczyzn tekstylnych w środkowych partiach paneli ściennych, na których miała być prezentowana bogata kolekcja obrazów. Ten unikalny projekt dekoracji ściennej został ostatecznie zrealizowany dopiero po śmierci pomysłodawczyni aranżacji i fundatorki tkanin w 1729 roku.

Zachowana korespondencja pomiędzy Marią Zofią Czartoryską (1699-1777; primo voto Denhoff) - córką Elżbiety Sieniawskiej, spadkobierczynią Pałacu Wilanowskiego, a marszandem André Contessą ujawnia szczegóły dotyczące zakupu tkanin do wystroju Sypialni Króla. W liście z 19 sierpnia 1730 roku Contessa informował swoją klientkę i jednocześnie zachwalał, iż otrzymał „Materye Bleu mourent ze srebrem najnowszej mody” oraz złożył jej propozycję kupna. Zakup ten zostaje potwierdzony w kolejnym liście marszanda do Marii Denhoff z 22 sierpnia 1730 roku. Pisze w nim Contessa o wysłaniu jej sztuki materii „Bleu mourent ze srebrem modną"2. W korespondencji brak informacji, gdzie owa „materya” została utkana, a jest to zagadnienie szczególnie nurtujące współczesnych badaczy ze względu na wyjątkowo oryginalny wzór weluru. Poszukiwania w archiwach francuskich manufaktur

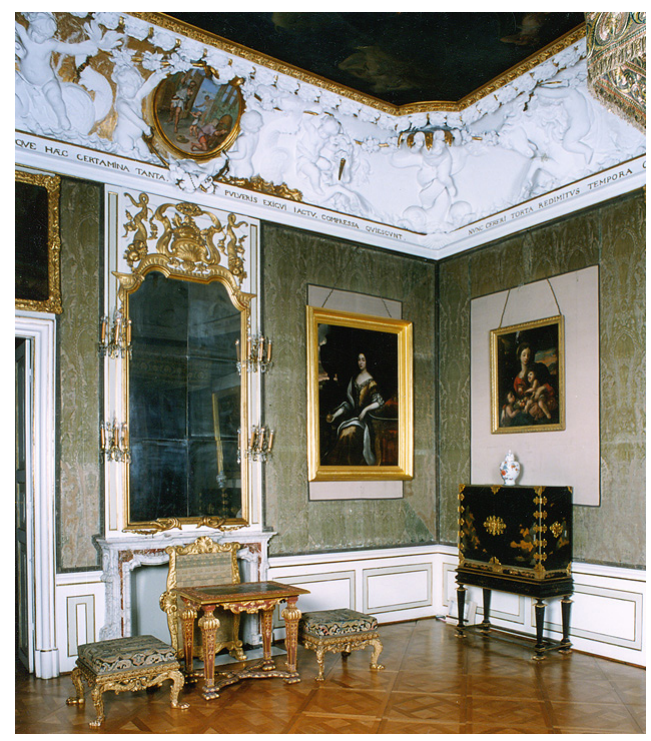

Il. 1. Sypialnia Króla - wnętrze przed pracami konserwatorskimi, fot. W. Holnicki działających nieprzerwanie od XVIII wieku po dzień dzisiejszy nie dały pozytywnych efektów, także poszukiwania w archiwach włoskich nie przyniosły zadowalających rezultatów.

\section{Tkaniny ścienne z Sypialni Króla}

Centralny element kompozycji weluru stanowi pień drzewa, wewnątrz którego widnieje gigantyczny kwiat o gruszkowatym kształcie przypominający oset. Po bokach centralnie usytuowanego pnia znajdują się połamane, butwiejące konary oraz porastające je dziko paprocie. Wiele elementów przyrody zestawionych jest ze sobą w zaskakujący sposób, podkreślający abstrakcyjność motywu ${ }^{3}$ (il. 2).

Ornament weluru tworzy jedwabna okrywa włosowa cięta, a tłem wzoru jest gładka, kremowa powierzchnia o splocie

\footnotetext{
2 M. Żukowska, Zespół obiciowych aksamitów wzorzystych tzw. velours de Gênes we wnętrzach Pałacu wilanowie, „Ochrona Zabytków”, 1996, nr 2, s. 130.

3 P. Marabelli, A project to reproduce a 280-year-old velvet. Meeting today's challenges with the skills of the past, "Jacquard", 2012, nr 70, s. 42-44.
} 
rypsowym lansowana srebrną blaszką (czyste srebro o próbie 1000). Obecnie skorodowana powierzchnia metalu daje efekt poziomych brązowoszarych pasków w tle tkaniny, podczas gdy pierwotnie blask srebra stwarzal wrażenie lustrzanego tła dla oryginalnego wzoru tkaniny, odbijającego promienie światła i mieniącego się w jego blasku. Motyw dekoracyjny weluru z sypialni królewskiej „przypomina trochę koronkowe kompozycje osiowo-symetryczne, a także pewne elementy z wzorów bizarre, spotykane na tkaninach francuskich z pierwszej ćwierci XVIII wieku"4. Analogii do wzoru można poszukiwać na jedwabnych lampasach i adamaszkach powstałych w manufakturach francuskich w latach 1700-17305. Wzór wilanowskiego weluru z całą pewnością należy do tej grupy tkanin, choć wyróżnia się wśród nich odmienną techniką tkacką, nietypową i dość trudną w dostosowaniu do finezyjnych koronkowych wzorów łączonych z ornamentami typu bizzare charakterystycznych dla tkanin brokatowych czy adamaszków ${ }^{6}$. Według podziału Thorntona wilanowski welur zakwalifikować można do tzw. drugiej fazy stylu bizarre, która swój początek miała w manufakturach weneckich.

\section{Stan zachowania tkanin z Sypialni Króla}

Tkaniny ścienne z Sypialni Króla, podobnie jak tekstylia z pozostałych apartamentów królewskich, od momentu montażu na ścianach komnat, pozostawały na nich niezmiennie aż do przełomu XIX i XX wieku, kiedy to po

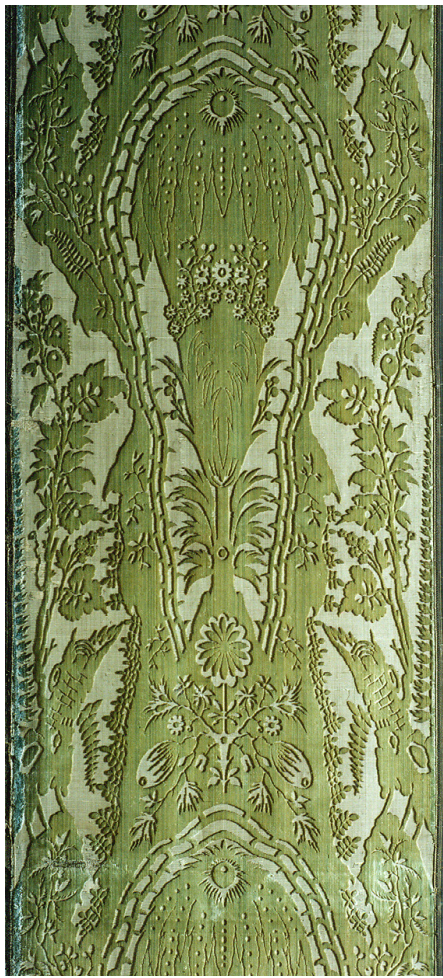

Il. 2. Raport XVIII-wiecznego weluru wzorzystego z Sypialni Króla, fot. W. Holnicki raz pierwszy zdjęto blejtramy, aby przeprowadzić kompleksowe prace naprawcze. Tkaniny eksponowane są nieprzerwanie od ok. $1730 \mathrm{r}$. w pomieszczeniu o zmiennych niegdyś warunkach klimatu, zależnych od pór roku. W przeszłości wahania temperatury i wilgotności względnej oraz naświetlenia daleko wykraczały poza przyjęte dziś normy. Warunki klimatyczne panujące w komnacie królewskiej nigdy w przeszłości nie były stabilne, co miało wielki wpływ na kondycję znajdujących się tam tkanin.

Szczególnie groźne dla zabytkowych tkanin ściennych okazało się światło. Największe zniszczenia barwy weluru wzorzystego z Sypialni Króla spowodowane zostały przez wieloletni długotrwały, nieograniczony dostęp promieniowania ultrafioletowego [UV] i podczerwonego [IR], które przyczyniły się do nieodwracalnych fizyko-chemicznych i optycznych zmian?.

\footnotetext{
M. Żukowska, op. cit., s. 134.

B. Markowsky, Europäische Seidengewebe des 13. - 18. Jahrhunderts, Köln 1979, s. 301-309.

P. Thornton, Baroque and Rococo Silks, London 1965, il. 34 A, 44 A, 44 B, 55 A, s. 110, 114, 111.

7 Szerzej o zagrożeniach z tym związanych pisze A. Pawlak, Światło w muzeum - dylematy konserwatora, „Wilanowski Informator Konserwatorski”, 2013, s. 117-130.
} 
Stan zachowania tkanin ściennych nie pozwalał na dalsze eksponowanie ich na ścianach apartamentu. Podjęto decyzję o zdjęciu, zabezpieczeniu i bezpiecznym przechowywaniu oryginalnego weluru w Magazynie Zbiorów Muzealnych Muzeum Pałacu w Wilanowie. Zastąpić go miała rekonstrukcja. Celem było odtworzenie pierwotnego osiemnastowiecznego wyglądu dekoracji ściennych w Sypialni Króla.

\section{Barwa weluru z Sypialni Króla na przestrzeni wieków}

Przyglądając się obecnie barwie weluru wzorzystego z Sypialni Króla, można określić ją jako szarozielonożółtą kompozycję na kremowoszarym tle. Dekoloryzacja barwników oraz wpływ substancji, jakimi zaimpregnowane było płótno, na które pierwotnie naszyto tkaniny ścienne, spowodowały drastyczną zmianę koloru i zupełnie inny wizualnie odbiór draperii.

W 2009 roku przeprowadzono na Wydziale Chemii Uniwersytetu Warszawskiego badania barwników. Zastosowano metodę wysokosprawnej chromatografii cieczowej (HPLC) połączonej z tandemową spektrometrią mas (MS/MS) z jonizacją przez elektrorozpylanie $(\mathrm{ESI})^{8}$. Próbki do badań pobrane zostały z różnych miejsc tkaniny. Jako barwnik użyty do farbowania przędzy okrywy włosowej weluru zidentyfikowano indygo oraz janowiec barwierski (Genista tinctoria L.). Przy czym zawartość indyga w każdej z próbek była znacznie większa niż janowca barwierskiego. W próbkach pobranych z fragmentów zdegradowanych, mocno zmienionych kolorystycznie (bardziej zielonych), zawartość indyga była wyraźnie mniejsza niż w tych pobranych z miejsc znajdujących się pod galonami, gdzie światło prawie nie docierało. Ponadto podczas analiz wykryto także izatynę - produkt degradacji indyga. Dla wszystkich próbek zawartość izatyny jest pozytywnie skorelowana z zawartością indygotyny, tzn. próbki zawierające niewielkie ilości indyga zawierają także stosunkowo niedużo izatyny.

Główną przyczyną zmiany koloru weluru było zatem zjawisko fotodegradacji, choć można także podejrzewać wpływ szelaku na barwę tkanin. Oryginalne płótno, na które naszyte były dekoracyjne tkaniny ścienne pokryte było żółtobrązową żywicą (mieszaniną szelaku i gumy roślinnej ${ }^{9}$ ), aby włókna tkaniny lnianej osiągnęły właściwy stopień napięcia po nabiciu płótna na ramę drewnianego krosna ściennego. Przypuszczenia o wpływie szelaku na tkaninę można wysnuć na podstawie porównania weluru ściennego z Sypialni Króla z takim samym welurem tapicerującym wilanowskie XVIII-wieczne taborety, nie mającym kontaktu z szelakiem. Tkanina z taboretów jest znacznie mniej zielonożółta, a bardziej zielonoszara. Niestety jest to tylko hipoteza, której nie udało się potwierdzić podczas wykonywania analiz chemicznych (il. 3).

Pierwotna, oryginalna barwa weluru wzorzystego z Sypialni Króla intryguje i przyciąga wzrok. Wspominany w korespondencji marszanda Contessy ${ }^{10}$ do Marii Denhoff kolor bleu mourent to znany z XVIII-wiecznego wzornika barw ${ }^{11}$ kolor blamarantowy (fr. bleu

\footnotetext{
8 Technika pozwalającą na rozdzielenie i identyfikację naturalnych związków barwiących wchodzących w skład barwników organicznych używanych m.in. do barwienia tkanin.

9 Analiza w podczerwieni. K. Królikowska-Pataraja, Badania tkanin obiciowych z korpusu głównego pałacu $w$ Wilanowie, (mps), 2005, s. 47.

10 B. Czaja-Szewczak, 18th c. Wall Upholstery inside the King's Bedroom at Wilanów Palace and its Contemporary Reconstruction, "Jacquard", 2012, nr 70, s. 35.

11 I. Schiffermüller, Versuch eines Farbensystem, Vienna 1772, plate II (wiersz D), www.gutenberg-e.org/lowengard/C_Chap57.html (dostęp 5.10.2021).
} 
mourrant lub bleu pâle, łac. Pallide caeruleus, niem. Blaßblau, Bleumourant, Blümerant, Bleichblau). Kolor błękitny ale nie pospolity..., z domieszką mleka, jak ten widoczny na XVIII-wiecznej porcelanie $\mathrm{z}$ berlińskiej manufaktury ${ }^{12}$, lekko szary, rozmyty, sprawiający wrażenie gasnącego. Dyskusje nad pierwotną barwą weluru wzorzystego były burzliwe ${ }^{13}$, a to za sprawą ,wielu zachowanych odcieni”, których doszukać się można, analizując kolor zabytkowego weluru z Sypialni Króla. Zmieniający się na przestrzeni wieków kolor tkanin spowodowany działaniem światła przechodził powoli od jasnoniebieskiego, przez seledynowy do zieleni, co doskonale poświadczają zapisy w wilanowskich inwentarzach

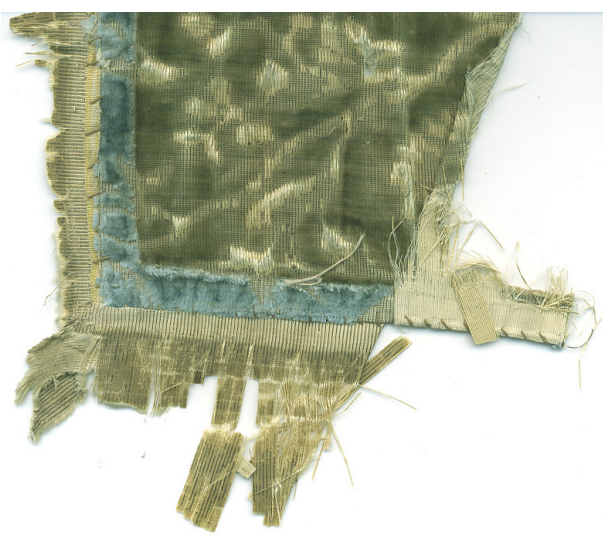

Il. 3. Fragment tkaniny taboretu z zachowanym kolorem bleu-mourant, fot. B. Czaja

Kolor obić ściennych - bleu mourant - miał wpływ na nazwę, jaką posługiwano się, mówiąc o tej komnacie pałacowej. W inwentarzu z 1743 r. pojawia się określenie Sypialni Króla - „Pokój drugi albo blamarantowo-srebrny”, natomiast w inwentarzu z 1793 r. zanotowano, iż na ścianach w sypialni znajduje się „obicie na srebrnym dnie kwiaty blamarantowe axamitne, wkoło Galony srebrne maiące”14, a także „Pokój drugi Blamarantowy”"15. Wiktor Czajewski w przewodniku po Wilanowie z 1903 r. pisał o Sypialni Króla - „Pokój ten wybity: tkaniną piękną, białą morową, srebrem przetykaną i ozdobiony ramami z materii w duże kwiaty seledynowego koloru"16.

W związku z przemianami kolorystycznymi weluru pokrywającego ściany apartamentu królewskiego, jakie zaszły na przestrzeni 300 lat, postanowiono do analizy i dyskusji nad pierwotną, oryginalną barwą tkaniny wykorzystać fragmenty znajdujące się w magazynie muzealnym, a pochodzące z kanapy i taboretów, niegdyś obitych tzw. resztkami pozostałymi po zaaranżowaniu welurem ścian Sypialni Króla. Wykorzystano w ten sposób wszystkie fragmenty cennej tkaniny, a jednocześnie apartament zgodnie z XVIII-wieczną modą wyposażony został w komplet mebli obitych tymi samymi tkaninami co obicia ścienne. Welur blamarantowy tapicerujący meble nie miał kontaktu z szelakiem, którym nasączone było płótno blejtramów ściennych, w związku z tym nie był narażony na zabarwienie na kolor

\footnotetext{
12 W 1784 roku, po czterech latach prac badawczych prowadzonych przez prof. Acharda w Königliche Porzellan-Manufaktur Berlin (KPM), udało się spełnić oczekiwania króla Fryderyka II Wielkiego i uzyskano delikatny matowy jasny odcień błękitu, tzw. bleu mourant, którym dekorowano ulubiony przez Jego Wysokość serwis „Neuzierat".

13 W komisjach brali udział: prof. dr hab. Juliusz Chrościcki, prof. Helena Hryszko, dr Krzysztof Chmielewski, dr Monika Stachurska, dyr. Paweł Jaskanis, Elżbieta Modzelewska, Paweł Baranowski, Anna Kwiatkowska, Tamara Przygońska, Anna Ekielska-Mardal, Marcin Chmielewski, Maciej Baran, Agnieszka Krzemińska, Anna Makulec, Barbara Czaja.

14 Inwentarz 1793, Inwentarz pałacu willanowskiego y Wszystkich w nim znayduiących Meblów, Obrazów etc. Diebus Septembris 1793 Spisany; AGAD, AGWil., Zarząd Muzeum w Wilanowie, 166; odpis - Dział Dokumentacji Naukowej - Mat. Źr. 110, s. 60.

15 Ibidem, s. 38.

16 W. Czajewski, Ilustrowany przewodnik po Warszawie, Warszawa 1892, s. 82.
} 
żółty, tak jak miało to miejsce w przypadku tkanin ściennych. Uznano, iż właśnie na obiciach meblowych należy szukać oryginalnej barwy weluru. Dokładne analizy fragmentów tekstyliów, szczególnie tych ukrytych między szwami łączącymi bryty tkanin, czy w miejscach, które zakryte były naszytym na welur dekoracyjnym galonem, przyniosły oczekiwany efekt. Wytypowano fragment z kolorem najmniej zmienionym czynnikami środowiskowymi, na którym mogła oprzeć się rekonstrukcja weluru do Sypialni Króla.

Kolor oryginalnego weluru wzorzystego z sypialni królewskiej nie był całkowicie jednolity. Łatwo zaobserwować na jego aksamitnej błękitnej powierzchni smugi, to tzw. abrasze ${ }^{17}$ będące efektem niedoskonałego sposobu farbowania barwnikami naturalnymi (il. 4).

Etap poszukiwania pierwotnej barwy był jednym z pierwszych kroków na drodze do rekonstrukcji tkaniny. Tradycja tkania welurów wzorzystych przetrwała do dziś we Francji i Włoszech. Tak jak w XVIII wieku istnieją tam manufaktury specjalizujące się w bogatych, niezwykle dekoracyjnych, wykonanych ze szlachetnych surowców tkaninach. Tekstylia tkane są na XVIII i XIX-wiecznych krosnach wspomaganych od 1805 roku maszyną Jacquarda ${ }^{18}$, a projekt wzoru powstaje obecnie przy wsparciu programu komputerowego. Jednak sam proces tkania odbywa się ręcznie, wymaga dużego doświadczenia, niezwykłej uwagi oraz skupienia tkacza i jest niezwykle czasochłonny. Dziennie powstaje $15 \mathrm{~cm}$ bieżących weluru o szerokości $53 \mathrm{~cm}^{19}$. Jest on tkany od początku do końca procesu przez jedną osobę, aby na całej długości tkaniny zmianom nie ulegała wysokość raportu wzoru. Każdy z tkaczy z inną siłą nacisku dobija nowo wprowadzony wątek i stąd prawdopodobieństwo wystąpienia różnic w wymiarach ornamentu.

Obecne sposoby barwienia przędzy eliminują powstawanie niedoskonałości wybarwień. Kolor całej ufarbowanej przędzy jest jednolity. Próbując odtworzyć w rekonstruowanym welurze wzorzystym efekt niejednolitości, rozedrgania oryginalnego koloru postanowiono, iż jedwabna przędza barwiona na kolor niebieski zostanie ufarbowana w kilku odcieniach. Dzięki temu uzyskano efekt abraszy (il. 5).

W styczniu 2011 roku zakończył się proces tkania weluru do Sypialni Króla, przeprowadzony w oparciu o zachowane tkaniny oryginalne oraz wyniki badań chemicznych i konserwatorskich. Do wykonania kopii użyto surowców identycznych z zastosowanymi w oryginale - przędzy jedwabnej i srebrnej blaszki (il. 6). Od 2012 roku nowy welur wzorzysty utkany we florenckiej manufakturze Fondazione Arte della Seta Lisio ${ }^{20}$ zdobi ściany Sypialni Króla pałacu w Wilanowie, natomiast oryginalną tkaninę po zabiegach konserwatorskich umieszczono w Magazynie Zbiorów Muzealnych. Jeden z brytów można oglądać w otwartej dla publiczności Galerii Magazynowej znajdującej się w budynku zwanym Markoniówką, przy południowym skrzydle rezydencji królewskiej.

\footnotetext{
17 Abrasz [fr. abrache, ang. abrash, arab. شرب (al abrasz)] - słowo pochodzenia arabskiego oznaczające różnicę odcienia jednego koloru występującą w tkaninie w postaci smug, pręg, mniej lub bardziej widocznych pionowych lub poziomych linii przebarwień, które są spowodowane nierównomiernym wybarwieniem przędzy wątku lub osnowy.

18 Maszyna Jacquarda - Joseph Marie Jacquard opracował metodę sterowania nitkami osnowy za pomocą kart perforowanych. Otwory w odpowiednich miejscach kart kierowały nicielnicami wybierającymi konkretne nitki osnowy odpowiedzialne za wzór na tkaninie.

19 J. Holyoke, The reconstruction of an 18th century laminated cut velvet for the King's Bedroom at Wilanów Palace by the Lisio Foundation in Florence, "Jacquard", 2012, nr 70, s. 39.

20 B. Czaja-Szewczak, J. Holyoke, XVIII-wieczne tkaniny ścienne z Sypialni Króla i ich wspótczesne rekonstrukcje, „Wilanowski Informator Konserwatorski”, 2013, s. 29-51.
} 
Il. 4. Fragment oryginalnego weluru z widocznymi na tkaninie abraszami, fot. W. Holnicki

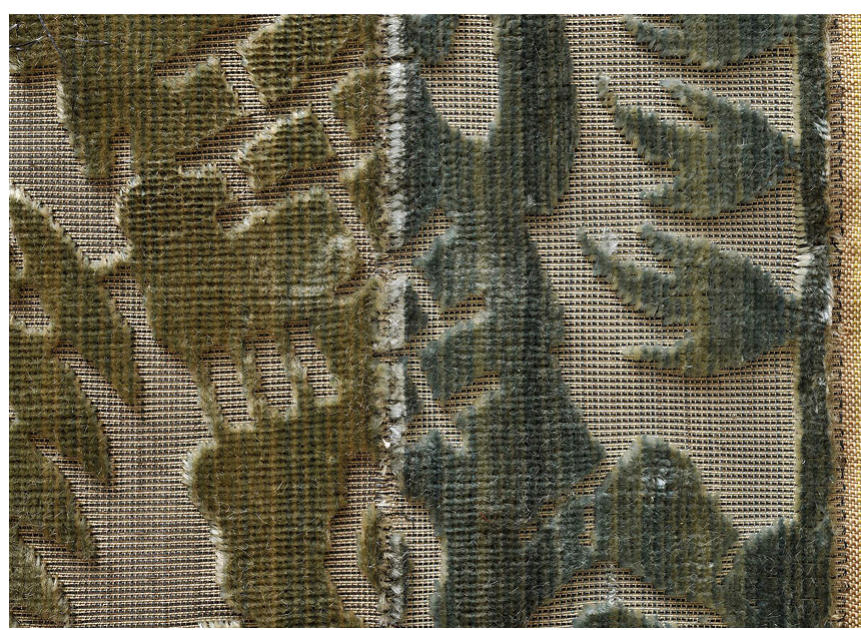

Il. 5. Fragment zrekonstruowanego jedwabnego weluru, fot. A. Indyk

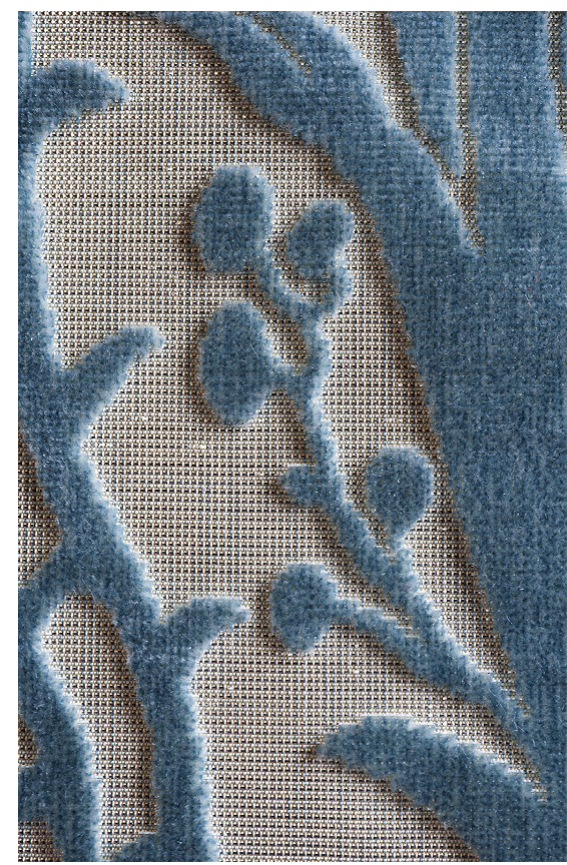




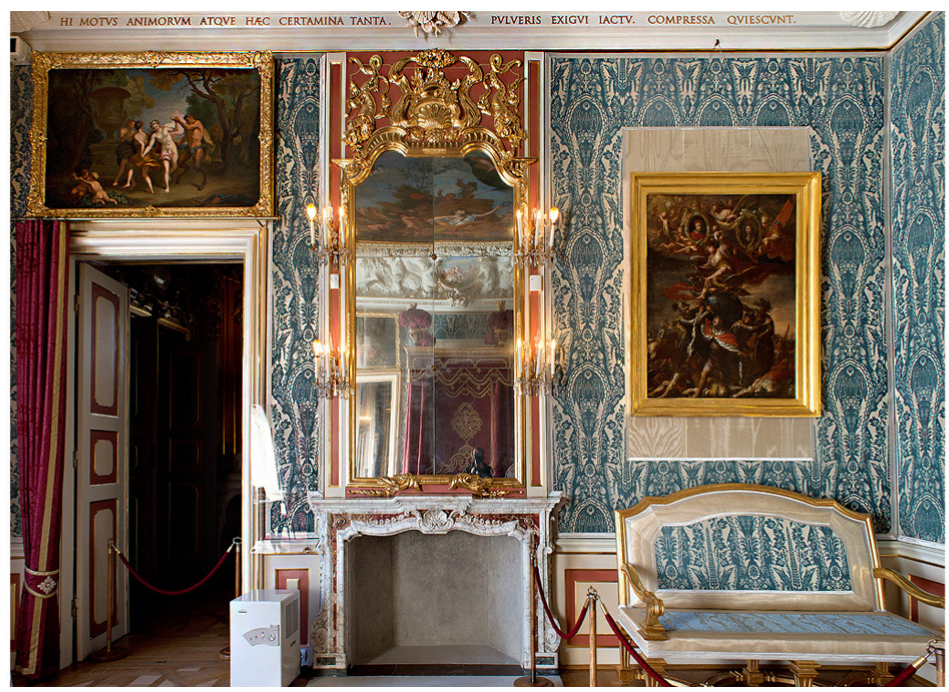

Il. 6. Wnętrze Sypialni Króla po pracach konserwatorskich ze zrekonstruowanym welurem wzorzystym na ścianach, fot. A. Indyk

\section{Bibliografia}

Czaja-Szewczak B., 18th c. Wall Upholstery inside the King's Bedroom at Wilanów Palace and its Contemporary Reconstruction, "Jacquard", 2012, nr 70, s. 34-38.

Czaja-Szewczak B., Holyoke J., XVIII-wieczne tkaniny ścienne z Sypialni Króla i ich wspótczesne rekonstrukcje, „Wilanowski Informator Konserwatorski”, 2013, s. 29-51.

Czajewski W., Ilustrowany przewodnik po Warszawie, Warszawa 1892.

Holyoke J., The reconstruction of an 18th century laminated cut velvet for the King's Bedroom at Wilanów Palace by the Lisio Foundation in Florence, "Jacquard", 2012, nr 70, s. 38-42.

Inwentarz 1793, Inwentarz pałacu willanowskiego y Wszystkich w nim znayduiacych Meblów, Obrazów etc. Diebus Septembris 1793 Spisany; AGAD, AGWil., Zarząd Muz. W Wilanowie nr 166; odpis - Dział Dokumentacji Naukowej - Mat. Źr. 110.

Królikowska-Pataraja K., Badania tkanin obiciowych z korpusu głównego pałacu w Wilanowie, (mps), 2005.

Marabelli P., A project to reproduce a 280-year-old velvet. Meeting today's challenges with the skills of the past, "Jacquard", 2012, nr 70, s. 42-44.

Markowsky B., Europäische Seidengewebe des 13. - 18. Jahrhunderts, Köln 1979.

Pawlak A., Światto w muzeum - dylematy konserwatora, „Wilanowski Informator Konserwatorski”, 2013, s. 117-130.

Schiffermüller I., Versuch eines Farbensystem, Vienna 1772, plate II (wiersz D), www.gutenberg-e. org/lowengard/C_Chap57.html (dostęp 5.10.2021).

Thornton P., Baroque and Rococo Silks, London 1965.

Żukowska M., Zespół obiciowych aksamitów wzorzystych tzw. velours de Gênes we wnętrzach Pałacu $w$ Wilanowie, „Ochrona Zabytków”, 1996, nr 2, s. 126-137. 